\title{
A Preliminary Study on Application of Countryside Landscape in Landscape Design of Small Contemporary Towns of China
}

\author{
Li Yan \\ Art and Design School \\ Huanghe Science and Technology College \\ Zhengzhou, Henan, China, 450000
}

\begin{abstract}
Small towns under influence of multiple factors become a new type of human settlement. As new urbanization picks up speed in China, the prime time comes for rapider development of small towns. Countryside landscape is a kind of humanized natural beauty, which brings into environment natural idyllic scenery and simple regional culture. The paper attempts to introduce countryside landscape into landscape design of small towns, with a view to finding principles and methods to apply countryside landscape into landscape design of small contemporary towns of China. This includes integration of styles and features of countryside landscape on a macro-level, and application of countryside landscape into landscape design of small contemporary towns on a micro-level.
\end{abstract}

Keywords-Countryside Landscape; Small Towns; Landscape Design; Integration of Styles and Features

\section{INTRODUCTION}

As the new landscape clashes with the old inside China's small contemporary towns, small towns began to lose its original characters gradually during large-scaled development. Under these conditions, we as design researchers faces the urgent problems of how to save those would-be-lost landscape resources, how to make countryside resources serve landscape design of small contemporary towns in the high time of development, and how to come up with the design which features both development of contemporary society and characters of small towns.

The paper, written under such social conditions, discusses about the application of countryside landscape into landscape design of small contemporary towns, and tries to infuse "countryside landscape" into landscape design of China's small contemporary towns, with a view to providing some new ideas and methods for constructing small towns.

\section{ON THE MACRO-LEVEL-INTEGRATING STYLES AND} FEATURES OF COUNTRYSIDE LANDSCAPE OF CHINA's SMALL CONTEMPORARY TOWNS

Landscape styles and features are a combination of folk customs and tradition, cultural tradition, terrain, landform and other geographic characters. When it comes to landscape design of small contemporary towns in China, the landscape styles and features, which originate from the inside and form at the outside, reflect the intangible grace of physical forms of small contemporary towns. On a macro-level, styles and features of countryside landscape showcase unique features of small towns, which result in harmony between men and nature, men and men, and men and society. Integration in the paper is construed as overall consideration of established environment, which is higher than environmental management of general preservation and renovation measures. Therefore, construction of small towns should entail reasonable integration of unique local countryside landscape so as to ensure environmental beautifulness, regional culture and agreeable habitableness of small towns in China.

\section{A. Basic Principles in Integrating Landscape Styles and Features of Small Contemporary Towns}

\section{1) The Principle of Overall Planning and Coordination}

Countryside landscape derives itself from the nature and human life, which fully expresses human worship for nature. In landscape design of small contemporary towns, we should consider landscape as a whole and coordinate different elements to reach uniformity among them, so as to form a more harmonious relationship between men and environment, among living things, between living and nonliving things, and among ecological systems for better preservation. At designing landscape, overall harmony among ecological, cultural and aesthetic functions of countryside landscape should be pursued. Of course, design of countryside landscape cannot be done without considering environment and ecology, whose focus should be put on basic geographical conditions, climate conditions, architectural characters and cultural atmosphere, etc. To some extent we can say that landscape development pursues coordination between men and environment, men and men (the earlier generation and the later generation). The principle of coordination is basic to sustainable development. On organizing land uses, it should start from overall development of landscape, so as to guarantee relative completeness and reasonableness of the organization and coordination between the natural side and the landscape side of countryside. While pursuing rapid economic development, we should also give full consideration to nature and environment and maintain a balanced and coordinated relationship between economic development and resource conservation. Countryside landscape requires uniformity in diverse patterns. 
Uniformity in changes and change in uniformity are key to applying the principles of uniformity in renovating and designing countryside landscape.

\section{2) The Principle of Intensive Integration and Natural} Ecology

Inheritance of countryside landscape is why the landscape keeps existing. The landscape reflects countryside customs and styles of a specific time of the history. In the course of time, many great thinkers repeatedly emphasize that the true meaning of aestheticism is to guide individuals' values according to the overall benefits of the society and thus cultivate social members who live up to the social moral code. Using elements of countryside landscape to design landscape of small towns is the as such in that it also considers interests of the social majority so as to find thing on which people give their agreements and ensure longevity of the landscape. Countryside landscape is mainly decided by the natural ecological environment, so development and renewal of countryside must be based on natural, geographical and climatic conditions in the local area. On the whole, countryside landscape can not exist independently in the environment, it must exist as an integral part of the natural environment and play an active role in pushing forward development of the surrounding environment, especial the complete landscape design.

\section{3) The Principle of Adapting to Local Conditions and} Showing Local Characters.

Countryside landscape come into being under effects of specific natural and humanistic environment, as a result, countryside landscape at different areas will represent different styles and features. Countryside landscape is a vehicle of human civilization, which under influence of natural environment, cultural cultivation, and folk customs and tradition, present distinct forms at different areas. There exist in many a small contemporary towns in China a lot of aboriginal countryside landscape resource, which laid a good foundation for shaping landscape of small contemporary towns. Integration of countryside landscape should be done by focusing on the whole and countryside characters and using the principles of landscape ecology. By doing this, the countryside specialty will be preserved; cultural resource can be used rationally and maintain sustainable development. Thus, the new habitable landscape system of small towns of contemporary China will be created.

4) The Principle of True Advisibility and Economic Feasibility

According to characters of countryside landscape, integration of landscape styles and features should on one hand preserve the original form as much as possible while new elements are also introduced into it; on the other hand it should also adhere to the original creative concept as much as possible while new ideas can be used skillfully to gratify special requirements. Landscape advisability will result in social acceptability, which is the key to whether the development strategy can be implemented smoothly. Any development strategy going against social reality and unacceptable by society cannot follow social development. Therefore, it will only end in an idle dream. One important precondition for application of countryside landscape is that advisability in choice of countryside landscape means to satisfy men's production and living needs and ensure to accept by the society. Therefore, ensuring advisability in choice of countryside landscape and social acceptability become important prerequisite for application of countryside landscape. Additionally, because money put into use by some small towns is limited, we must abide by the principle of economic feasibility at integrating styles and features of countryside landscape so as to achieve the best results with the least input.

5) The Principle of Function Renewal and Public Participation

Countryside landscape during its coming-into-being and development has very clear functions and relatively independent users. However, when the landscape is used in a new environment, its original functions and users will change.

Public participation is very important to landscape development. In order to guarantee orderly development of landscape design, the public should first renew their conception and embrace the idea of returning of countryside landscape. Designers should enter into mind of the public and think from perspective of the public, so as to encourage the public adapt their thinking. While organizing countryside landscape of small towns, we should give full consideration to effects of changeable or unknown factors on landscape design, therefore, leave sufficient space for changing orientation of countryside landscape development. Summarily, we should have both a back door in the form of organization and a leeway in land use of the project.

\section{B. Methods to Integrate Styles and Features of Countryside Landscape}

The basic thinking behind integration of styles and features of countryside landscape of small contemporary towns mainly includes two aspects, namely, improving ecological environment and preserving historical styles and features.

\section{1) Improving Ecological Environment in Small Towns}

Countryside environment is a complete landscape ecological system which is highly artificialized. It plays an important role in solidifying natural ecological structure inside small towns and is conductive to adjusting ecological environment of small towns. Spatial structure of landscape of small towns is comprised of base material, patches and corridors. From the perspective of landscape ecology, terrain and landform of countryside landscape constitutes the basic material of landscape structure. Countryside settlement, woodland, water body and natural vegetation are the patches of landscape. Rivers, roads, forest belts and tree hedges makes the corridors. Management of countryside ecological environment will focus on preserving and renewing patches that are important to ecological environment of small towns, as well as on adding new cultural characters into their original natural attributes. Thus, a new landscape structure is formed. For example, we will improve and optimize land use to achieve harmony with the nature. 
Ecological structure should be established from the following aspects:

a) To guarantee wholeness of basic countryside vegetation through intensive use of land, so as to exert ecological function of vegetation in landscape.

b) Production and living patches should be built on natural patches and take the form of corridors.

c) While respecting terrain and landform, natural vegetation patches should be preserved and added into the landscape.

d) To make structural adjustment to landscape space with a view to realizing orderly and organic integration of production, living and natural patches.

e) To protect biological diversity and landscape visual diversity from the perspective of landscape heterogeneity.

2) Preservation of Historical Styles and Features of Small Towns

First priority of preservation of countryside historical styles and features is to preserve countryside settlements inside small towns. This includes preservation and reproduction of historical relics, overall coordination of architectural styles and features, reappearance of fold customs and inheritance of local culture. Local people, after a long time of experience accumulation and creation, has cultivated bit by bit their own countryside landscape culture like architectural style, production life and countryside settlement, etc. During construction of small towns, we should upholding the principle of preservation of countryside landscape by repairing or renovating existing landscape, by doing this, we not only add new useful functions but also infuse new life into the landscape. Preserving countryside landscape is also protecting crystallization of human wisdom and helping carry on historical inheritance.

\section{ON THE MiCRO-LEVEL -- PRINCIPLES AND StRATEgIES OF APPLICATION OF COUNTRYSIDE LANDSCAPE INTO LANDSCAPE DESIGN OF SMALl TOWNS OF CONTEMPORARY CHINA}

\section{A. Principles of Application of Countryside Landscape into} Landscape Design of Small Contemporary Towns

\section{1) Respecting local natural conditions}

On designing landscape inside small towns, human intervention should be reduced as much as possible by respecting local natural conditions, like terrain, climate, vegetation and animals.

\section{a) Respecting Original Terrain}

As new functional spaces were ushered into small towns, more and more basic land is bulldozed or re-split, which eradicates completely the original historical inheritance and relics and natural vegetation. In addition, facts like excessive hardening of land surface, change of soil structure, destruction of animal habitats, and even changes of illumination and sound intensity, all wreak severe effects on properties of landscape. Therefore, respecting original terrain and landform at applying countryside landscape to landscape design of small towns is a way to cultivate the place.

\section{b) Respecting the Climate}

The climate will decide or influence people's vision and touch by illumination, temperature, humidity, air flow, animals and vegetations, so it must be respected on designing landscape.

\section{c) Respecting Countryside Vegetation}

Countryside vegetation, as a native biocenosis in the area, has already adapted to the natural environment in the area. During landscape design of small towns, using countryside vegetation to treat landscape will not only ensure healthy growth of vegetation but also present regional features.

\section{2) Representing Local Historical and Humanistic} Characters

As people accumulate experience in customs, culture and art, and religious belief, connotation of countryside landscape is ever developing and expanding to catch up with the times. We must establish an environmental outlook with deep cultural connotation, thus we can make landscape with strong vigor. Landscape is a carrier of traditional culture and modern civilization, which supplies a frame for sensing people's social attributes. During landscape design of small towns, we can showcase local history, culture, and humanistic resource through countryside landscape, which plays an important role in continuing the culture of small towns.

\section{3) Respecting Needs and Aestheticism of Local People}

First, the designer should have a clear understanding that designing countryside landscape is to serve the life of local people. We should give respect to their behaviours and taboos and design for their life. Second, interpretation of countryside landscape is a process of the designer communicating emotion and attitudes with local people. Therefore, during design of countryside landscape, it is indispensable to communicate and exchange with local people. Only by doing this, can they accept and acknowledge the landscape being designed and renovated, and become a part of it naturally. Only by sufficient communication with local people, can the designer better grasp their true needs and make landscape truly adaptable to their production life.

4) Conservation, Reasonable Development and Exploitation of Local Resource

During landscape design of small towns, we use stone and trees from the local area and adopt simple but practicable methods to build landscape, so as to encourage construction of conservation-oriented landscape.

\section{B. Strategy of Application of Countryside Landscape into Landscape Design of Small Contemporary Towns \\ 1) Using Simple Design Ideas}

By simple design we do not mean simplicity in shape, color and texture as much as peculiar styles and characters with rich cultural connotation. Simple design aspires to naturalness and greenness. When doing creation work on the original landscape, it tries to obviate any exaggerated expression or too many sundry details so as to preserve the pureness and truthfulness of original countryside landscape. To adopt simple design ideas in designing landscape of small towns is also a way to make good use of original materials in 
the local area and show full respect to local culture. We will make direct use of physical and spiritual resource of countryside as much as possible with a view to best showing originality of countryside landscape. Adopting simple design ideas is also a good way to save on cost and resource.

2) Combining Modern Technology with Countryside Elements

The tenet followed in countryside landscape design is to focus on flexible use of materials and pluralistic technologies. As different areas communicate and blend with each other, the countryside shows moderate changes in its form and renewal in its cultural thoughts.

In the clash between homogeneous and heterogeneous cultures and at the cross point of new and old cultures, countryside landscape design should absorb new ideas, new concepts and natural designs to build a better environment. While technologies advance rapidly in today's society, we should put more emphases on combining modern technology with the nature and culture of countryside. Landscape design of small towns should witness more combination of information technology, intelligence technology and ecological technology, representatives of modern technology, with regional culture and traditional technology. Thus, we can produce excellent works that have modernness and historical significance.

\section{3) Drawing Inspiration from the Nature}

Factors like local material, climate, soil and water will reflect most directly the environment, which are also direct representation of simple ecological outlook on nature. While designing landscape of small towns, we should use existing countryside landscape elements and draw our inspiration from the nature. For better exploitation and protection of natural environment we must consider the two following aspects: firstly, how will the landscape integrate with the terrain, landform and vegetation of the base land and how will the integration be represented; secondly, how do we use factors of the base land such as climate, etc, to create artificial landscape which is habitable, agreeable, natural and ecological.

\section{4) Merging with Surrounding Landscape}

Landscape cannot exist independent of its surrounding environment. It must rely on some environment and receives influences from it. While designing landscapes of small towns, we must consider the relationship between regional environment and the landscape, so as to make the landscape and its surrounding environment reciprocal to each other. A delicate infusion between the natural and artificial beauty will greatly enhance expressiveness and vigor of the product and make artificial beauty an integral part of the natural environment. Artificiality of the landscape will be greatly reduced by merging the landscape into its surrounding environment through introducing countryside vegetation into the landscape. 